\title{
Особенности раннего постсуицидального
}

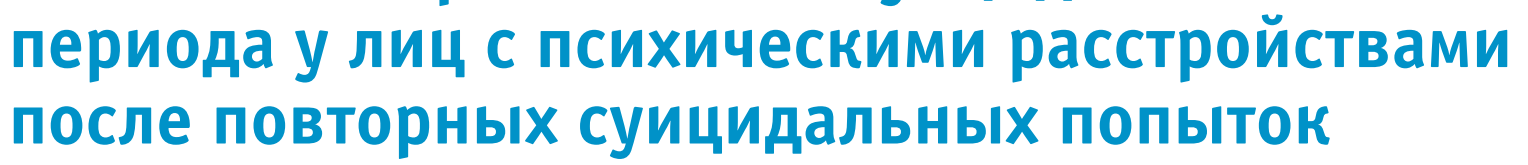

\author{
Н.С. Рутковская, В.К. Шамрей, Е.С. Курасов, А.И. Колчев, В.В. Нечипоренко \\ ФГБвоу Во «Военно-медицинская академия имени С.М. Кирова» Министерства обороны Российской Федерации; Россия, \\ 2. Санкт-Петербург
}

\section{PEЗЮME}

\begin{abstract}
Цель исследования: изучить особенности раннего постсуицидального периода у лиц с психическими расстройствами, совершивших суицидальные попытки.

Дизайн: ретроспективное клиническое исследование.

Материалы и методы. Проведено исследование особенностей раннего постсуицидального периода у 260 лиц с психическими расстройствами (шизофренического спектра, органическими, аффективными, невротическими, аддиктивными, личностными расстройствами и умственной отсталостью), совершивших суицидальные попытки. Средний возраст суицидентов составил 43,5 $\pm 17,7$ года. Мужчины и женщины были представлены примерно в равном количестве - 134 (51,5\%) и 126 (48,5\%) соответственно (р > 0,05). Средняя длительность госпитализации $-42,7 \pm 43,2$ койко-дня. Использовались клинико-психопатологический, психометрический и математико-статистический методы.

Результаты. Выделены основные типы раннего постсуицидального периода: наиболее часто встречались варианты постсуицидального периода по типу критического постсуицида $(n=73,28,1 \%)$ и отрицания суицидальной попытки $(n=55,21,2 \%)$, реже всего - аналитический постсуицидальный период ( $\mathrm{n}=23,8,8 \%)$. Установлено, что $77(29,6 \%)$ пациентов психиатрического стационара с суицидной попыткой в анамнезе совершили повторный суицид. Наиболее частыми способами совершения попытки суицида у этих больных были отравление медикаментами $(n=41,53,2 \%)$ и нанесение самопорезов $(n=26,33,8 \%)$, а 40,3\% из них в момент совершения повторной суицидальной попытки находились в состоянии алкогольного опьянения. У больных, совершивших повторную суицидальную попытку, значимо чаще отмечались манипулятивный и суицидально-фиксированный типы постсуицидального периода. Выявлено, что у пациентов с психическими расстройствами, совершивших повторные суицидные попытки, низкий уровень социальной адаптации в сферах профессиональной деятельности и общего отношения к жизни.

Заключение. Обнаруженные особенности постсуицидального периода у лиц с психическими расстройствами, совершивших суицидальные попытки, целесообразно учитывать при планировании и проведении мероприятий вторичной психопрофилактики. Дальнейшее изучение данной проблемы у различных категорий больных с учетом поиска предикторов совершения повторных суицидных попыток, а также оценки эффективности проведенных ранее психопрофилактических мероприятий позволит проводить их более дифференцированно и снизить в целом риск суицидального поведения людей с психическими расстройствами.

Ключевые слова: суицид, повторная суицидальная попытка, тип постсуицидального периода, психическое расстройство, социальная адаптация.
\end{abstract}

Вклад авторов: Рутковская Н.С. - сбор материала, его обработка и написание текста статьи, Шамрей В.К. - утверждение статьи в печать, Курасов Е.С. - разработка концепции, дизайна исследования, Колчев А.И. - разработка концепции, дизайна исследования, Нечипоренко В.В. - разработка концепции, дизайна исследования.

Конфликт интересов: авторы заявляют об отсутствии возможных конфликтов интересов.

Для цитирования: Рутковская Н.С., Шамрей В.К., Курасов Е.С., Колчев А.И., Нечипоренко В.В. Особенности раннего постсуицидального периода у лиц с психическими расстройствами после повторных суицидальных попыток. Доктор.Ру. 2020; 19(9): 59-64. D0I: 10.31550/17272378-2020-19-9-59-64

\section{Characteristics of the Early Post-suicidal Period after Repeat Suicide Attempts in Patients with Mental Disorders}

\section{N.S. Rutkovskaya, V.K. Shamrey, E.S. Kurasov, A.I. Kolchev, V.V. Nechiporenko}

S.M. Kirov Military Medical Academy (a Federal Government-funded Military Educational Institution of Higher Education), Russian Federation Ministry of Defense; 17A Botkinskaya St., St. Petersburg, Russian Federation 194044

\section{ABSTRACT}

Study Objective: To study characteristics of the early post-suicidal period after suicide attempts in patients with mental disorders.

Study Design: This was a retrospective clinical study.

Materials and Methods: The study looked at the characteristics of the early post-suicidal period after suicide attempts in a group of 260 subjects with mental disorders (schizophrenia-spectrum disorders, organic, affective, neurotic, addictive, or personality disorders, or

Рутковская Наталья Сергеевна - преподаватель кафедры психиатрии ФГБвоу Во «ВМА им. С.М. Кирова» Минобороны России. 194044, Россия, г. Санкт-Петербург, ул. Боткинская, д. 17a. eLIBRARY.RU SPIN: 4525-1580.E-mail: rutkovskayanatalia@yandex.ru Шамрей Владислав Казимирович - Ә. м. н., профессор, заведующий кафедрой психиатрии ФГБВоУ ВО «ВМА им. С.М. Кирова» Минобороны России. 194044, Россия, 2. Санкт-Петербург, ул. Боткинская, д. 17A. https://orcid.org/0000-0002-1165-6465. E-mail: ShamreyV.K@yandex.ru Курасов Евгений Сергеевич (автор для переписки) - Ә. м. Н., доцент, профессор кафедры психиатрии ФГБВОУ ВО «ВМА им. С.М. Кирова» Минобороны России. 194044, г. Санкт-Петербург, ул. Боткинская, д. 17A. eLIBRARY.RU SPIN: 4961-0342. E-mail: doc4678@mail.ru (Окончание на с. 60.) 
intellectual disability). The mean age of patients who attempted suicide was $43.5 \pm 17.7$ years. The numbers of men and women were almost equal: $134(51.5 \%)$ and $126(48.5 \%)$, respectively $(p>0.05)$. The mean duration of hospitalization was $42.7 \pm 43.2$ bed-days. The study methods included clinical examinations, psychopathological assessments, psychometrics, and statistical-mathematical methods.

Study Results: The authors identified the following main types of early post-suicidal period: the critical type $(n=73,28.1 \%)$ and denial of a suicide attempt $(n=55,21.2 \%)$ were the most common and the analytical type $(n=23,8.8 \%)$ was the least common. The study determined that $77(29.6 \%)$ psychiatric inpatients with a history of attempting suicide made another attempt. The most common methods of attempted suicide in this group of patients included poisoning with medications $(n=41,53.2 \%)$ and self-cutting $(n=26,33.8 \%)$, and $40.3 \%$ were under the influence of alcohol at the time of the repeat suicide attempt. Among the patients who made a repeat suicide attempt, manipulative and suicide-fixated types of post-suicidal period were observed significantly more often. Patients with mental disorders who made repeat suicide attempts showed poor social adjustment in their professional life and overall attitude toward life.

Conclusion: The characteristics of the post-suicidal period identified in patients with mental disorders who have made a repeat suicide attempt should be taken into consideration when planning and providing secondary preventive mental healthcare services. Further investigation of these characteristics in various groups of patients, combined with a search for predictive factors for repeat suicide attempts, as well as evaluation of the effectiveness of previously provided preventive mental health care, will make it possible to better tailor these services and reduce the overall risk of suicidal behavior in people with mental disorders.

Keywords: suicide, repeat suicide attempt, type of post-suicidal period, mental disorder, social adjustment.

Contributions: Dr. N.S. Rutkovskaya collected and processed information, and wrote the paper. Dr. V.K. Shamrey approved the final version of the manuscript submitted for publication. Dr. E.S. Kurasov, Dr. A.I. Kolchev, and Dr. V.V. Nechiporenko developed the concept and design of the study.

Conflict of interest: The authors declare that they do not have any conflict of interests.

For citation: Rutkovskaya N.S., Shamrey V.K., Kurasov E.S., Kolchev A.I., Nechiporenko V.V. Characteristics of the Early Post-suicidal Period after Repeat Suicide Attempts in Patients with Mental Disorders. Doctor.Ru. 2020; 19(9): 59-64. (in Russian). D0I: 10.31550/1727-2378-2020-19-9-59-64

\section{ВВЕДЕНИЕ}

Результаты современных исследований свидетельствуют о том, что значительный процент лиц, совершивших попытку самоубийства, страдает различными психическими расстройствами, доля которых колеблется от 15\% до 80\% [1-5]. Так, в целом ряде исследований различные психические нарушения выявляются в подавляющем большинстве (до 95\%) случаев у лиц, совершивших как суицидальную попытку [6-9], так и завершенный суицид [2, 10-14]. Подчеркивается, что среди выживших после совершенных попыток психически больных до 60\% совершают суицид в течение полугода после выписки (как правило, в течение первого месяца) [15-17]. При этом повторные попытки самоубийства обычно совершаются уже не под влиянием аффекта, а достаточно обдуманно, что существенно повышает вероятность завершенного суицида $[18,19]$.

В настоящее время ведущая суицидальная концепция модель стресс-диатеза, в которой первостепенная роль отводится предрасположенности к суицидальному поведению [1, 20-22]. Отмечается, что повторные суицидальные попытки чаще совершаются людьми одинокими, безработными, бездомными, страдающими психическими и соматическими заболеваниями, злоупотребляющими алкоголем и наркотиками, имеющими в анамнезе правонарушения, являющимися жертвами сексуального насилия и т. д. [4, $23,24]$. Наиболее же значимый «индикатор» риска потенциального самоубийства - предшествующая суицидальная попытка ${ }^{1}[2,25]$.

Вместе с тем вопросы предотвращения повторных суицидов остаются недостаточно изученными, поэтому выявление предикторов повторных суицидальных попыток у лиц с психическими расстройствами остается одной из наиболее актуальных проблем современной суицидологии ${ }^{2}[10,11,26,27]$.

Цель исследования: изучить особенности раннего постсуицидального периода у лиц с психическими расстройствами, совершивших суицидальные попытки.

\section{МАТЕРИАЛЫ И МЕТОДЫ}

Исследование выполнялось на базе клиники психиатрии ФГБВОУ ВО «Военно-медицинская академия имени С.М. Кирова» и Санкт-Петербургского ГБУЗ «Психиатрическая больница № 1 им. П.П. Кащенко» в 2016-2019 гг. Обследованы 260 пациентов с различными психическими расстройствами: шизофренического спектра - 62 (23,8\%), с органическими - $69(26,5 \%)$, аффективными - $26(10,0 \%)$, невротическими - $29(11,2 \%)$, аддиктивными - $46(17,7 \%)$, личностными расстройствами - $26(10,0 \%)$, с умственной отсталостью - $2(0,8 \%)$.

Средний возраст суицидентов составил 43,5 \pm 17,7 года. Мужчины и женщины были представлены примерно в равном количестве - 134 (51,5\%) и 126 (48,5\%) соответственно ( $>0,05)$. Средняя длительность госпитализации $-42,7 \pm 43,2$ койко-дня. Средний возраст больных шизофренией, шизотипическим и бредовым расстройствами составил 40,4 \pm 14,4 года, расстройствами аффективной сферы - 47,5 $\pm 14,5$ года, органическими психическими расстройствами - 58,9 $\pm 18,9$ года. Пациенты, страдающие наркотическими аддикциями, невротическими расстройствами и синдромом зависимости от алкоголя были в возрасте от 30

Колчев Александр Иванович - д. м. н., профессор, доцент кафедры психиатрии ФГБВоу ВО «Военно-медицинская академия им. С.М. Кирова» Минобороны России. 194044, Россия, г. Санкт-Петербург, ул. Боткинская, д. 17A. eLIBRARY SPIN: 4128-7377. ORCID: https://orcid.org/00000003-0398-2039.E-mail: a.kolchev@mail.ru

Нечипоренко Валерий Владимирович - профессор кафедры психиатрии ФГБВоу ВО «ВМА им. С.М. Кирова» Минобороны России, д. м. н., профессор. 194044, г. Санкт-Петербург, ул. Боткинская, д. 17A. eLIBRARY.RU SPIN: 2549-1634. E-mail: szun@yandex.ru (Окончание. Начало см. на с. 59.)

\footnotetext{
${ }^{1}$ Колумбийская шкала оценки тяжести суицидальности (C-SSRS). URL: http://rncpg.org/wp-content/uploads/2019/04/C-SSRS.pdf (дата обращения — 15.01.2020).

2 Hamilton psychiatric rating scale for depression. URL: https://dcf.psychiatry.ufl.edu/files/2011/05/HAMILTON-ANXIETY.pdf (дата обращения — 15.01.2020).
} 
до 40 лет: $30,9 \pm 4,3,36,5 \pm 11,9$ и 39,1 $\pm 10,9$ года соответственно. Наиболее молодую возрастную группу (до 30 лет) составили пациенты с умственной отсталостью $(26,0 \pm 2,8$ года) и расстройствами личности $(27,1 \pm 8,2$ года).

На первом этапе исследования обследованы 260 специально отобранных больных с верифицированной психической патологией (проходивших стационарное лечение), совершивших суицидные попытки, а на втором углубленно изучены 77 (29,6\%) из них, совершившие повторный суицид после выписки из психиатрического стационара.

Основным методом исследования являлся клинико-психопатологический. В целях объективизации психопатологических нарушений и оценки степени суицидального риска использовались следующие психометрические шкалы: Шкала депрессии Гамильтона (Hamilton psychiatric rating scale for depression $)^{3}$ и Колумбийская шкала оценки тяжести суицида (Columbia Suicide Severity Rating Scale) ${ }^{4}$.

Оценивали также уровень общего психосоциального функционирования с приминением шкалы социальной адаптации, разработанной на кафедре психиатрии Военномедицинской академии им. С.М. Кирова (Шамрей В.К., Рустанович А.В., 2000) [3]. Данная шкала содержит 6 пунктов, ранжированных по 5-балльной системе, определяющих образовательный уровень, семейный статус, трудовую занятость, характер межличностных отношений, досуг, общее отношение к жизни. В зависимости от интегрального показателя выделялись четыре группы: с низким (менее 2 баллов), удовлетворительным (2-2,4 балла), хорошим (2,52,9 балла) и высоким (3 балла и более) уровнем социальной адаптации.

Статистическая обработка материала осуществлялась с помощью пакета прикладных программ Microsoft Excel for Windows, Statistica 10.0. Данные представлены в виде средних арифметических со стандартными квадратичными отклонениями $(m \pm \sigma)$. Средние групповые значения, дисперсия результатов исследования, стандартное отклонение, минимальное и максимальное значения показателей рассчитаны с помощью модуля описательной статистики. Различия считали статистически значимыми при $\mathrm{p}<0,05$.

\section{РЕЗУЛЬТАТЫ}

Характеристика 260 пациентов с психическими расстройствами, совершивших первые суицидные попытки, приведена в таблице 1. Установлено статистически значимое преобладание мужчин в группах суицидентов, страдающих аддиктивной патологией, - наркоманиями (F11.2, F12.2 и F15.2 по МКБ-10 - 78,6\%) и алкоголизмом (F10.2 - 75,0\%), а женщин - в группе аффективных расстройств (F33.1, F33.2, F33.3 - 69,2\%) $(p<0,05)$.

Незначительное преобладание мужчин выявлено среди пациентов с расстройствами личности (F60.3, F60.4 $57,7 \%)$, а также невротическими, связанными со стрессом и соматоформными расстройствами (F41.2, F43.22, $\mathrm{F} 43.25-51,7 \%)$. В свою очередь, незначительное преобладание женщин отмечалось среди больных шизофренией, шизотипическими и бредовыми расстройствами (F20.0, F25.1 - 51,6\%) и органическими психическими расстройствами (F06.3, F06.4 - 56,5\%).

Наиболее частыми способами совершения попытки суицида были отравление медикаментами $(\mathrm{n}=112,43,1 \%)$, а также нанесение множественных самопорезов ( $n=90,34,6 \%)$.
Таблица 1 / Table 1

Характеристика обследованных

больных психическими расстройствами, совершивших суицидальные попытки

Characteristics of patients with mental disorders who made more than one suicide attempt

\begin{tabular}{|l|l|l|}
\hline $\begin{array}{c}\text { Коды нозологических } \\
\text { форм (Международная } \\
\text { классификация болезней } \\
\text { 10-го пересмотра) / Disorder } \\
\text { (International Classification of } \\
\text { Diseases 10 code) }\end{array}$ & $\begin{array}{c}\text { Мужчины / } \\
\text { Мan, } \mathbf{n}(\%)\end{array}$ & $\begin{array}{c}\text { Женщины / } \\
\text { Female, } \\
\mathbf{n}(\%)\end{array}$ \\
\hline F01-F09 $(n=69)$ & $30(43,5)$ & $39(56,5)$ \\
\hline F10 $(n=32)$ & $24(75,0)^{*}$ & $8(25,0)$ \\
\hline F11-F19 $(n=14)$ & $11(78,6)^{*}$ & $3(21,4)$ \\
\hline F20-F29 $(n=62)$ & $30(48,4)$ & $32(51,6)$ \\
\hline F30-F39 $(n=26)$ & $8(30,8)^{*}$ & $18(69,2)$ \\
\hline F40-F48 $(n=29)$ & $15(51,7)$ & $14(48,3)$ \\
\hline F60-F69 $(n=26)$ & $15(57,7)$ & $11(42,3)$ \\
\hline F70-F79 $(n=2)$ & $1(50,0)$ & $1(50,0)$ \\
\hline
\end{tabular}

* 3Аесь и Аалее в статье: $\mathrm{p}<0,05$.

$*$ Here and below: $\mathrm{p}<0.05$.

В ходе работы всех обследуемых разделили на группы в соответствии с типами постсуицидального периода, согласно модифицированной классификации постсуицидального периода, предложенной А.Г. Амбрумовой (1980). В ее основу положены следующие характеристики: 1) актуальность суицидогенного конфликта; 2) степень фиксированности на суицидальных тенденциях и 3) особенности отношения к совершенной попытке [28].

Перечисленные критерии позволили распределить больных по четырем типам постсуицидальных состояний: критический, манипулятивный, аналитический и суицидально-фиксированный. Вместе с тем среди пациентов встречались и лица с осложненным типом постсуицида, при котором судить о критическом отношении к суицидальной попытке можно было лишь с большой долей условности. Отдельную группу составляли больные, полностью отрицающие суицидальные действия, несмотря на явные их свидетельства наличие факта суицидальных действий при отсутствии грубого органического повреждения головного мозга и соответствующего типа амнезии. Эти пациенты были выделены в две самостоятельные группы: «формально-критический (осложненный) постсуицид» и «отрицание суицидальной попытки».

Анализ соотношения типов постсуицидального периода у обследованных больных показал (табл. 2), что наиболее часто встречались варианты критического постсуицида (28,1\%) и отрицания суицидальной попытки (21,2\%). Реже всего обнаруживался аналитический тип постсуицидального периода.

Изучение особенностей постсуицидального периода пациентов с различной психической патологией выявило (табл. 3), что в группе лиц с критическим постсуицидальным типом преобладали больные, страдающие органической психической патологией $(35,6 \%)$ и невротическими (связанными со стрессом) расстройствами (19,1\%). При манипулятивном постсуициде чаще встречались пациенты, страдающие органической психической патологией $(31,0 \%)$ и расстройствами личности $(23,8 \%)$.

${ }^{3}$ Hamilton psychiatric rating scale for depression...

${ }^{4}$ Колумбийская шкала оценки тяжести суицидальности (C-SSRS)... 
Таблица 2 / Table 2 б

Соотношение типов постсуцидального периода у пациентов психиатрического стационара, совершивших суициАальные попытки

Absolute and relative numbers of psychiatric inpatients who have made more than one suicide attempt by type of post-suicidal period

\begin{tabular}{|l|l|}
\hline \multicolumn{1}{|c|}{$\begin{array}{c}\text { Типы постсуицидального } \\
\text { периода / Tyре of post-suicidal } \\
\text { period }\end{array}$} & $\begin{array}{c}\text { Количество } \\
\text { пациентов / number } \\
\text { of patients, } \mathbf{n ~ ( \% ) ~}\end{array}$ \\
\hline Критический / Critical & $73(28,1)$ \\
\hline Манипулятивный / Manipulative & $42(16,2)$ \\
\hline Аналитический / Analytical & $23(8,8)$ \\
\hline $\begin{array}{l}\text { Суицидально-фиксированный / } \\
\text { Suicide-fixated }\end{array}$ & $40(15,4)$ \\
\hline Осложненный / Complicated & $27(10,3)$ \\
\hline $\begin{array}{l}\text { Отрицание суицидальной попытки / } \\
\text { Denial of suicide аttempt }\end{array}$ & $55(21,2)$ \\
\hline Всего / Tоtal & $260(100,0)$ \\
\hline
\end{tabular}

В современных работах указывается, что депрессивные нарушения могут выступать в качестве предиспонирующего фактора суицида различной степени $[5,8,9,24]$. В связи С этим в ходе дальнейшего исследования проанализировано наличие клинически очерченной депрессивной симптоматики (с использованием Шкалы депрессии Гамильтона) у пациентов с психическими расстройствами с различными типами постсуицидального периода (табл. 4).

Установлено, в частности, что депрессивные расстройства, предшествовавшие суицидальной попытке, преобладали только в группе пациентов с осложненным постсуицидальным периодом (81,5\%) и существенно реже встречались среди больных с критическим $(4,1 \%)$ и манипулятивным $(4,8 \%)$ постсуицидальным периодом.

Дальнейшие исследования (второй этап) показали, что 77 $(29,6 \%)$ пациентов из обследованных ранее (на первом этапе) совершили повторные суицидные попытки: 23 (29,9\%) человека, страдавших органическими психическими расстройствами, $19(24,7 \%)$ - расстройствами шизофренического спектра, $12(15,6 \%)$ - личностной патологией, $7(9,1 \%)-$ расстройствами адаптации, $6(7,8 \%)-$ расстройствами депрессивного

Таблица 3 / Table 3

Типы постсуицидального периода у больных с различными психическими патологиями, $\mathrm{n}(\%)$ Types of post-suicidal period in patients with various mental disorders, $\mathrm{n}(\%)$

\begin{tabular}{|l|l|l|l|l|l|l|}
\hline $\begin{array}{c}\text { Рубрики } \\
\text { Международной } \\
\text { классификации } \\
\text { болезней } \\
\text { 10-го пересмотра / } \\
\text { International } \\
\text { Classification of } \\
\text { Diseases 10 code }\end{array}$ & $\begin{array}{c}\text { Критический } \\
\text { тип / Critical }\end{array}$ & $\begin{array}{c}\text { Манипулятив- } \\
\text { ный тип / } \\
\text { Мanipulative }\end{array}$ & $\begin{array}{c}\text { Аналити- } \\
\text { ческий тип / } \\
\text { Analytical }\end{array}$ & $\begin{array}{c}\text { Суицидально- } \\
\text { фиксирован- } \\
\text { ный тип / } \\
\text { Suicide-fixated }\end{array}$ & $\begin{array}{c}\text { Осложненный } \\
\text { тип / } \\
\text { Complicated }\end{array}$ & $\begin{array}{c}\text { Отрицание } \\
\text { суицидальной } \\
\text { потыти / } \\
\text { Denial of suicide } \\
\text { attempt }\end{array}$ \\
\hline F01-F09 & $26(35,6)$ & $13(31,0)$ & $7(30,4)$ & $10(25,0)$ & 0 & $13(23,6)$ \\
\hline F10 & $11(15,1)$ & $5(11,9)$ & 0 & $2(5,0)$ & $4(14,8)$ & $10(18,1)$ \\
\hline F11-F19 & $2(2,7)$ & $4(9,5)$ & $1(4,4)$ & $5(12,5)$ & 0 & $2(3,6)$ \\
\hline F20-F29 & $4(5,5)$ & $2(4,8)$ & $9(39,1)$ & $8(20,0)$ & $23(85,2)$ & $16(29,1)$ \\
\hline F30-F39 & $11(15,1)$ & $2(4,8)$ & $4(17,3)$ & $7(17,5)$ & 0 & $2(3,6)$ \\
\hline F40-F49 & $14(19,1)$ & $5(11,9)$ & $1(4,4)$ & $5(12,5)$ & 0 & $4(7,3)$ \\
\hline F60-F69 & $4(5,5)$ & $10(23,8)$ & $1(4,4)$ & $3(7,5)$ & 0 & $8(14,5)$ \\
\hline F70-F79 & $1(1,4)$ & $1(2,4)$ & 0 & 0 & 0 & 0 \\
\hline Bcero / Total & $73(100,0)$ & $42(100,0)$ & $23(100,0)$ & $40(100,0)$ & $27(100,0)$ & $55(100,0)$ \\
\hline
\end{tabular}

Таблица 4 / Table 4 ?

Наличие депрессивного синдрома у больных с разАичными типами постсуицидального периода (Шкала Аепрессии Гамильтона), n (\%)

Depressive syndrome in patients with various types of post-suicidal period (Hamilton Depression Scale), n (\%)

\begin{tabular}{|l|l|l|}
\hline \multicolumn{1}{|c|}{ Типы постсуицида / Туре of post-suicidal period } & \multicolumn{1}{|c|}{$\begin{array}{c}\text { С проявлениями } \\
\text { депрессии / With signs } \\
\text { of depression }\end{array}$} & $\begin{array}{c}\text { Без проявлений } \\
\text { депрессии / Without } \\
\text { signs of depression }\end{array}$ \\
\hline Критический / Critical $(\mathrm{n}=73)$ & $3(4,1)$ & $70(95,9)^{*}$ \\
\hline Манипулятивный / Manipulative $(\mathrm{n}=42)$ & $2(4,8)$ & $40(95,2)^{\star}$ \\
\hline Аналитический / Analytical $(\mathrm{n}=23)$ & $8(34,8)$ & $15(65,2)^{\star}$ \\
\hline Суицидально-фиксированный / Suicide-fixated $(\mathrm{n}=40)$ & $7(17,5)$ & $33(82,5)^{*}$ \\
\hline Осложненный / Сотрlicated $(\mathrm{n}=27)$ & $22(81,5)$ & $5(18,5)^{*}$ \\
\hline Отрицание суицидальной попытки / Denial of suicide attempt $(\mathrm{n}=55)$ & $12(21,8)$ & $43(78,2)^{*}$ \\
\hline Всего / тоtal $(\mathrm{n}=260)$ & $54(20,8)$ & $206(79,2)^{*}$ \\
\hline
\end{tabular}


спектра, 5 (6,5\%) - синдромом зависимости от алкоголя, $4(5,1 \%)$ - наркоманиями, $1(1,3 \%)$ - олигофренией.

Средний возраст этих больных составил 40,6 \pm 17,4 года. Мужчины и женщины были представлены примерно в равном количестве - 41 (53,2\%) и 36 (46,8\%) соответственно ( $p>0,05)$. Средняя длительность госпитализации $-38,5 \pm 24,3$ койко-дня. Наиболее частыми способами совершения повторной попытки суицида, как и первичной, являлись отравление медикаментами $(53,2 \%)$ и нанесение множественных самопорезов (33,8\%).

Среди пациентов с повторными суицидами 31 (40,3\%) в момент совершения суицидальной попытки находились в состоянии алкогольного опьянения. При этом среди них было значимо больше мужчин - 20 (26,0\%) против $11(14,3 \%)$ женщин $(\mathrm{p}<0,05)$.

Анализ особенностей совершения первой и повторных суицидальных попыток у обследованных пациентов (табл. 5) показал, что некоторые из них совершали «комбинированные» суицидальные попытки (например, наносили самопорезы и одновременно совершали попытку отравления).

\section{Таблица 5 / Table 5}

Особенности совершения первичной и повторной суициАных попыток у больных с психическими расстройствами, n (\%)

Methods of suicide used in the first and the repeat attempts by patients with mental disorders, $\mathrm{n}(\%)$

\begin{tabular}{|c|c|c|}
\hline $\begin{array}{c}\text { Особенности совершения } \\
\text { суицидных попыток / Method } \\
\text { of suicide }\end{array}$ & $\begin{array}{c}\text { Первая } \\
\text { попытка / } \\
\text { First attempt } \\
(\mathrm{n}=260)\end{array}$ & $\begin{array}{c}\text { Повторная } \\
\text { попытка / } \\
\text { Repeat } \\
\text { attempt } \\
(\mathbf{n}=77)\end{array}$ \\
\hline $\begin{array}{l}\text { Отравление медикаментами / } \\
\text { Poisoning with medications }\end{array}$ & $112(43,1)$ & $41(53,2)^{*}$ \\
\hline Самопорезы / Self-cutting & $90(34,6)$ & $26(33,8)$ \\
\hline Самоповешение / Self-hanging & $20(7,7)$ & $4(5,2)$ \\
\hline $\begin{array}{l}\text { Попытка падения с высоты / } \\
\text { Attempted fall from a height }\end{array}$ & $21(8,1)$ & $4(5,2)$ \\
\hline $\begin{array}{l}\text { Отравление бытовым газом / } \\
\text { Poisoning by natural gas }\end{array}$ & $6(2,3)$ & $1(1,3)$ \\
\hline Самоудушение / Self-suffocation & $2(0,8)$ & 0 \\
\hline $\begin{array}{l}\text { Самоповреждение головы / } \\
\text { Self-injury to the head }\end{array}$ & $2(0,8)$ & 0 \\
\hline $\begin{array}{l}\text { Введение в вену воздуха / } \\
\text { Insufflation of air into a vein }\end{array}$ & $2(0,8)$ & 0 \\
\hline $\begin{array}{l}\text { Падение под транспорт / } \\
\text { Jumping in front of a vehicle }\end{array}$ & $1(0,4)$ & 0 \\
\hline Самоподжог / Self-immolation & $1(0,4)$ & 0 \\
\hline $\begin{array}{l}\text { Химический ожог пищевода / } \\
\text { Chemical burn to the esophagus }\end{array}$ & $2(0,8)$ & $1(1,3)$ \\
\hline $\begin{array}{l}\text { Попытка утопления / Attempted } \\
\text { drowning }\end{array}$ & $2(0,8)$ & $1(1,3)$ \\
\hline $\begin{array}{l}\text { Голодание с целью суицида / } \\
\text { Suicidal fasting }\end{array}$ & $2(0,8)$ & $1(1,3)$ \\
\hline $\begin{array}{l}\text { Передозировка наркотика / } \\
\text { Drug overdose }\end{array}$ & $1(0,4)$ & $1(1,3)$ \\
\hline $\begin{array}{l}\text { Комбинированная попытка / } \\
\text { Combination of methods }\end{array}$ & $10(3,8)$ & $2(2,6)^{*}$ \\
\hline $\begin{array}{l}\text { Наличие алкогольного } \\
\text { опьянения / Alcoholic } \\
\text { intoxication }\end{array}$ & $84(32,3)$ & $31(40,3)^{*}$ \\
\hline
\end{tabular}

Значительно чаще это происходило при первых попытках $3,8 \%$ против 2,6\% ( $<205)$. Установлено также, что при повторных попытках значимо чаще, чем при первых, имели место самоотравление медикаментами $(53,2 \%)$ и совершение их в состоянии алкогольного опьянения. При повторных суицидных попытках не зафиксированы отдельные способы их совершения, отмеченные ранее (при первичных попытках): самоудушение, самоповреждение головы, введение в вену воздуха, падение под транспорт и самоподжог.

Соотношение типов постсуицидального периода у пациентов с психическими расстройствами, совершивших однократные и повторные суицидальные попытки, представлено в таблице 6.

у больных, совершивших повторную суицидальную попытку, значимо чаще наблюдались манипулятивный и суицидально-фиксированный типы постсуицидального периода $(22,1 \%$ и 19,5\% соответственно, р <0,05). При этом у лиц, совершивших только одну суицидальную попытку, значимо чаще имел место критический тип постсуицидального периода $(32,8 \%)(\mathrm{p}<0,05)$.

Исследование уровня общего психосоциального функционирования показало, что у пациентов, совершивших повторные суицидальные попытки, достаточно низкий уровень социальной адаптации в сфере работы (1,8 $\pm 1,1$ балла) и общего отношения к жизни $(1,6 \pm 0,9$ балла). В других сферах отмечался удовлетворительный уровень социальной адаптации: образовательный уровень (2,2 \pm 1,1 балла) и семейный статус $(2,1 \pm 0,9$ балла). Высокий уровень социальной адаптации выявлен в сферах межличностных отношений $(3,0 \pm 0,6$ балла) и досуга $(2,6 \pm 0,8$ балла), однако оценка этих сфер пациентами носила довольно субъективный характер.

Полученные данные свидетельствуют о том, что общая жизненная и профессиональная дезадаптация являются

Таблица 6 / Table 6 ?

Соотношение типов постсуциАального периода у пациентов психиатрического стационара, совершивших однократные и повторные суициАальные попытки, n (\%)

Absolute and relative numbers of psychiatric inpatients who have made single or repeat suicide attempts by type of post-suicidal period, n ( $\%)$

\begin{tabular}{|l|l|l|}
\hline \multicolumn{1}{|c|}{$\begin{array}{c}\text { Типы } \\
\text { постсуицидального } \\
\text { suicidal period }\end{array}$} & $\begin{array}{c}\text { Повторная } \\
\text { суицидальная } \\
\text { попытка / } \\
\text { Repeat suicide } \\
\text { attempt }\end{array}$ & $\begin{array}{c}\text { Однократная } \\
\text { суицидальная } \\
\text { попытка / } \\
\text { Single suicide } \\
\text { attempt }\end{array}$ \\
\hline Критический / Critical & $13(16,8)$ & $60(32,8)^{*}$ \\
\hline $\begin{array}{l}\text { Манипулятивный / } \\
\text { Мапірulative }\end{array}$ & $17(22,1)$ & $25(13,7)^{*}$ \\
\hline Аналитический / Analytical & $7(9,1)$ & $16(8,7)$ \\
\hline $\begin{array}{l}\text { Суицидально- } \\
\text { фиксированный / Suicide- } \\
\text { fixатеd }\end{array}$ & $15(19,5)$ & $25(13,7)^{*}$ \\
\hline $\begin{array}{l}\text { Осложненный / } \\
\text { Сотрlісатеd }\end{array}$ & $8(10,4)$ & $19(10,3)$ \\
\hline $\begin{array}{l}\text { 0трицание суицидальной } \\
\text { попытки / Denial of suicide } \\
\text { attemрt }\end{array}$ & $17(22,1)$ & $38(20,8)$ \\
\hline Всего / Тоtal & $77(100,0)$ & $183(100,0)$ \\
\hline
\end{tabular}


существенными факторами риска повторного суицида у пациентов с психическими расстройствами, несмотря на высокий уровень межличностной коммуникации и организации досуга.

\section{ЗАКЛЮЧЕНИЕ}

Выявленные нами особенности постсуицидального периода у лиц с психическими расстройствами, совершивших суицидальные попытки, целесообразно учитывать при планирова-

\section{ЛИТЕРATУPA / REFERENCES}

1. Farberow N.L., Ganzler S., Cutter F., Reynolds D. An eight-year survey of hospital suicides. Suicide Life Treat. Behav. 1971; 1(3): 184-202.

2. Haynes R.L., Marques J.K. Patterns of suicide among hospitalized mentally disordered offenders. Suicide Life Treat. Behav. 1984; 14(2): 113-25. DOI: 10.1111/j.1943-278x.1984.tb00342.x

3. Шамрей В.К., ред. Избранные лекции по клинической, экспериментальной и военной психиатрии. М.; 2007: 88-106. [Shamrey V.K., ed. Selected lectures on clinical, experimental, and military psychiatry. M.; 2007: 88-106. (in Russian)]

4. Kõlves $K$., de Leo D. Suicide methods in children and adolescents. Eur. Child Adolesc. Psychiatry. 2017; 26(2): 155-64. D0I: 10.1007/ s00787-016-0865-y

5. O'Connor D.B., Ferguson E., Green J.A., O'Carroll R.E., O'Connor R.C. Cortisol reactivity and suicidal behavior: Investigating the role of hypothalamic-pituitary-adrenal axis responses to stress in suicide attempters and ideators. Psychoneuroendocrinology. 2017; 75: 183-91. D0I: 10.1016/j.psyneuen.2016.10.019

6. Buzan R., Weissberg M.P. Suicide: risk factors and prevention. Ann. Rev. Med. 1992; 43: 37-46. D0I: 10.1146/annurev. me.43.020192.000345

7. Dennis B.B., Roshanov P.S., Bawor M., ElSheikh W., Garton S., DeJesus J. et al. Re-examination of classic risk factors for suicidal behavior in the psychiatric population. Crisis. 2015; 36(4): 231-40. DOI: 10.1027/0227-5910/a000342

8. Положий Б.С. Суициды в России и в Европе. М.: МИА; 2016. 212 c. [Polozhij B.S. Suicides in Russia and Europe. M.: MIA; 2016. 212 p. (in Russian)]

9. Семенова Н.Б. Распространенность и факторы риска самоубийств среди коренных народов: обзор зарубежной литературы. Суицидология. 2017; 1(26): 17-39. [Semenova N.B. Suicidal prevalence and risk factors in native peoples: the review of foreign data. Suicidology. 2017; 8(1): 17-39. (in Russian)]

10. Barraclough B.M. The suicide rate of epilepsy. Ascta Psychatr. Scand. 1987; 76(4): 339-45. DOI: 10.1111/j.1600-0447.1987. tb05616.x

11. Якобсон Дж.Л., Якобсон А.М. Секреты психиатрии. М.: МЕДпрессИнформ; 2007. 576 c. [Jacobson J.L., Jacobson A.M. Secrets of psychiatry. M.: MEDpress-Inform; 2007. 576 p. (in Russian)]

12. Mann J.J., Waternaux C., Haas G.L., Malone K.M. Toward a clinical model of suicidal behavior in psychiatric patients. Am. J. Psychiatry. 1999; 156(2): 181-9. DOI: 10.1176/ajp.156.2.181

13. Остроглазов В.Г., Лисина М.А. Клинико-психопатологическая характеристика состояний и лии, совершивщих суицидальные попытки. Журнал неврологии и психиатрии им. С.С. Корсакова. 2000; 6: 18-20. [Ostroglazov V.G., Lisina M.A. Clinical and psychopathological characteristics of status of persons who have committed suicide attempts. S.S. Korsakov Journal of Neurology and Psychiatry. 2000; 6: 18-20. (in Russian)]

14. Положий Б.С. Концептуальная модель суицидального поведе ния. Суицидология. 2015; 1: 3-7. [Polozhij B.S. Conceptual model of suicidal behavior. Suicidology. 2015; 1: 3-7. (in Russian)]

15. Нечипоренко В.В., Попик А.Д., Сергиенко А.В. Некоторые тенденции в современной суицидологии. В кн.: Актуальные проблемы современной неврологии, психиатрии и нейрохирургии. CПб.; 2003: 114-16. [Nechiporenko V.V., Popik A.D., Sergienko A.V. Some of the trends in modern suicidology. In: Current problems of нии и проведении мероприятий вторичной психопрофилактики. Дальнейшее изучение данной проблемы у различных категорий больных с учетом поиска предикторов совершения повторных суицидных попыток, а также оценки эффективности проведенных ранее психопрофилактических мероприятий позволит проводить их более дифференцированно и снизить в целом риск суицидального поведения людей с психическими расстройствами.

modern neurology, psychiatry and neurosurgery. SPb.; 2003: 11416. (in Russian)]

16. Попов Ю.В., Пичиков А.А. Суицидальное поведение у подростков. СПб.: CneuЛum; 2017. 366 c. [Popov Yu.V., Pichikov A.A. Suicidal behavior in adolescents. SPb.: SpecLit; 2017. 366 p. (in Russian)]

17. Suokas J., Lönnqvist J. Outcome of attempted suicide and psychiatric consultation: risk factors and suicide mortality during a five-year follow-up. Acta Psychiatr. Scand. 1991; 84(6): 545-9. DOI: 10.1111/j.1600-0447.1991.tb03191.x

18. Ducloux M., Barbotin M., Cuisinier J.C., Ferraci C., Demarchi J. Methods, motivation, and mortality of 263 cases of attempted suicide observed at the Hospital Principal, Dakar, during a five-year period. Bull. Soc. Med. Afr. Noire Land Fr. 1973; 18(3): 317-30.

19. Нечипоренко В.В., Шамрей В.К. Суицидология: вопросы клиники, диагностики и профилактики. СПб.: ВМедА; 2007. 528 с. [Nechiporenko V.V., Shamrey V.K. Suicidology: questions of clinic, diagnostics and prevention. SPb.: VMedA; 2007. 528 p. (in Russian)]

20. Днов К.В., Серегин Д.А., Ятманов А.Н. Профилактика суицидального поведения и медико-психологическое сопровождение военнослужащих. Казань: Бук; 2017. 96 c. [Dnov K.V., Seregin D.A., Yatmanov A.N. Prevention of suicidal behavior and medical and psychological support for military personnel. Kazan': Buk; 2017. 96 p. (in Russian)]

21. Положий Б.С., ред. Национальное руководство по суицидологии. М.: МИА; 2019. 600 c. [Polozhij B.S., ed. National manual of suicidology. M.: MIA; 2019. 600 p. (in Russian)]

22. Sundqvist-Stensman U.B. Suicides in close connection with psychiatric care: an analysis of 57cases in a Swedish country. Acta Psychiatr. Scand. 1987; 76(l): 15-20. D0I: 10.1111/j.16000447.1987.tb02856.x

23. Пашковский В.Е., Шамрей В.К., Софронов А.Г. и др. Суицидальное поведение и религиозность. Суицидология. 2015; 3: 30-41. [Pashkovskij V.E., Shamrey V.K., Sofronov A.G. et al. Suicidal behavior and religiosity. Suicidology. 2015; 3: 30-41. (in Russian)]

24. Тихоненко В.А. Покушения на самоубийство и их профилактика: Дис. ... д-р мед. наук. М.; 1981. 376 с. [Tihonenko V.A. Suicide attempts and their prevention: a doctoral dissertation. M.; 1981. 376 p. (in Russian)]

25. Любов Е.В., Паршин А.Н. Клинико-экономические исследования суицидального поведения. Суищидология. 2016; 11-28. [Lubov E.B., Parshin A.N. Clinical and economic studies of suicidal behavior. Suicidology. 2016; 3(22): 11-28. (in Russian)]

26. Каплан Г.И., Сэдок Б.Дж. Клиническая психиатрия из синопсиса nо психиатрии. М.: Медицина; 1994: 1-2. 672 с. [Kaplan H.I., Sadock B.J. Clinical psychiatry from synopsis of psychiatry. M.: Medicina; 1994: 1-2. 672 p. (in Russian)]

27. Розанов В.А., Кибитов А.О., Гайнетдинов Р.Р. и др. Современное состояние молекулярно-генетических исследований в суицидологии и новые возможности оценки риска суицида. Суицидология. 2019; 10(1): 3-20. [Rozanov V.A., Kibitov A.0., Gainetdinov R.R. et al. Molecular genetics studies insuicidology and new opportunities in risk assessment. Suicidology. 2019; 10(1): 3-20. (in Russian)]

28. Амбрумова А.Г., Тихоненко В.А. Диагностика суицидального поведения: методические рекомендации. М.; 1980. 48 с. [Ambrumova A.G., Tihonenko V.A. Diagnosis of suicidal behavior: methodical recommendations. M.; 1980. 48 p. (in Russian)] D 